Profesor dr Miroslav Demić, dipl. inž. Mašinski fakultet, Kragujevac

\section{RAZVOJ MODELA VOZAČA ZA UPRAVLJANJE VOZILOM TOKOM PRAVOLINIJSKOG KRETANJA}

UDC: 656.052 .42

Rezime:

Upravljanje vozilom na pravolinijskom putu spada u specijalan slučaj analize dinamičkog sistema vozač - vozilo - okruženje, jer podužno kretanje vozila podrazumeva aktivno učešce vozača u uslovima koji su definisani parametrima puta i vozila. U savremenoj literaturi postoje pokušaji modeliranja pomenutog sistema u uslovima pravolinijskog kretanja, ali, do sada, nije definisan opšteprihvaćeni model vozača. Problem se usložava činjenicom da se u razmatranje mora uzeti $i$ veoma složeno ponašanje motora i transmisije u dinamičkim uslovima. U radu je modeliran sistem vozač - vozilo u uslovima pravolinijskog kretanja radi praćenja zadate, najčešće, promenljive brzine vozila.

Ključne reči: vozač, vozilo, put, model.

\title{
DEVELOPMENT OF DRIVER MODEL FOR VEHICLE CONTROL DURING A STRIGHT LINE MOTION
}

Summary:

To drive the vehicle on a straight line road can be put as a special case analysis of a Driver-Vehicle-Environment dynamical system, because, longitudinal vehicle motion means that active driver participates in the conditions defined by road and vehicle parameters. In contemporary literature, there are some attempts of modeling the mentioned system in the case of a straight line drive, but, so far, there is no generally accepted model of a driver. It should be mentioned that the problem is more complex with fact that a very complex motor and transmission behavior must be assumed in dynamic conditions. There are some attempts of modeling the driver and vehicle in the case of straight line driving, with a goal of tracking the given, frequently variable vehicle speed.

Key words: driver, vehicle, road, model.

\section{Uvod}

Radi povećanja bezbednosti vozila, u poslednje vreme koriste se sistemi koji pomažu vozaču ili smanjuju njegovu ulogu tokom vožnje. To se, prvenstveno, postiže sistemima koji omogućavaju korekciju dejstva vozača na točak upravljača, vožnju u koloni, onemogućavanje blokiranja točkova, kontrolu pogonskih sila i sl. Kako su oni detaljno opisani u $[10,22]$, ovde o njima neće biti reči.
U ovom radu biće definisan model vozača za upravljanje vozilom tokom pravolinijske vožnje, pri izvršavanju zadatka praćenja zadate brzine, a problem je, radi ilustracije, prikazan na slici 1 .

Sa slike se vidi da se vozač ne može posmatrati odvojeno od vozila, jer on prati stvarnu i upoređuje je sa željenom - zadatom brzinom. U zavisnosti od njihove razlike, deluje na komandu za dovod goriva, pri čemu se javlja kašnjenje reakcija od trenutka utvrđivanja razlike brzina do trenutka realizacije pomeranja stopala. 


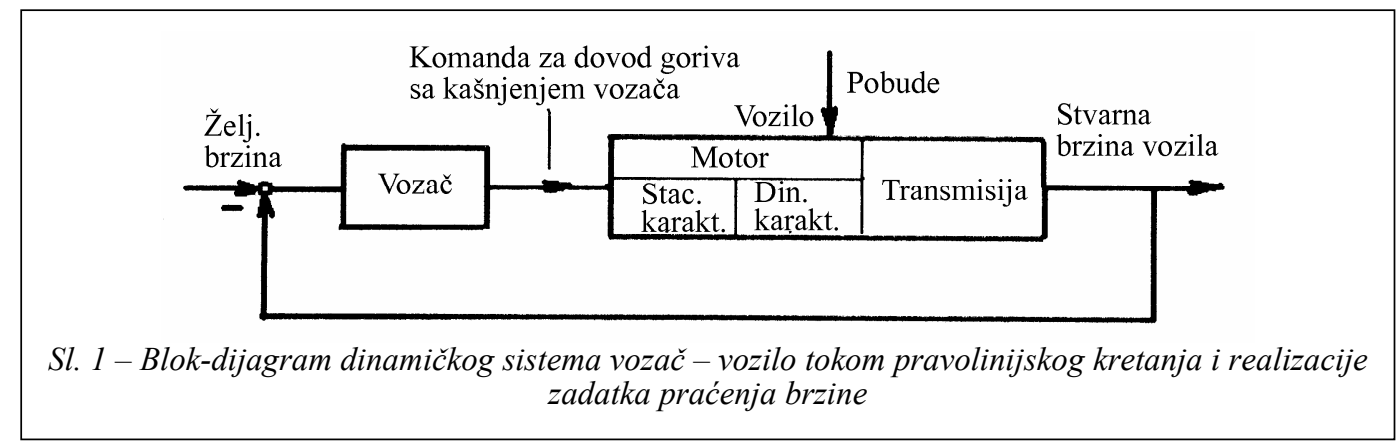

Vozilo, na koje deluju spoljašnje pobude (od vazduha, neravnina puta $\mathrm{i}$ sl.), predstavlja složeni dinamički sistem, jer obuhvata dinamičke karakteristike motora $\mathrm{i}$ transmisije, pa mu se tokom modeliranja mora posvetiti posebna pažnja. Uticaj makroprofila puta uzet je u obzir kroz podužni nagib puta, a o modeliranju posmatranog dinamičkog sistema biće više reči u narednom tekstu.

\section{Modeliranje vozača i vozila}

Vozač upravlja vozilom posredstvom: sistema za upravljanje, komandi koje definišu rad motora i transmisije i sistema za kočenje. Modeliranje dinamičkog sistema vozač - vozilo - okruženje tokom pravolinijske vožnje, u najopštijem slučaju, nije jednostavan zadatak, pa se uvode uprošćenja. Kako se pri modeliranju sistema vozača nailazi na veliki broj nepoznanica, ovde je usvojen koncept optimalnog upravljanja [1-11].

Modeliranje motora predstavlja problem sa više nepoznanica, tim pre što njegove karakteristike nisu stacionarne, kako se obično pretpostavlja, već zavise od načina delovanja na komandu za dovod goriva, opterećenja, broja obrtaja i sl. [19, 26, 31, 32].
Radi uprošćenja modela vozila, u konkretnom slučaju, posmatrana je idealna transmisija sa kontinualno varijabilnim menjačem, pogonskim mostom i odgovarajućim glavnim prenosnikom [13, 21].

\section{Modeliranje pogonske grupe}

Pogonska grupa posmatranog vozila obuhvata motor sa njegovim, u najopštijem slučaju, dinamičkim performansama, idealni kontinualno varijabilni menjač, pogonski most i točkove.

Problem modeliranja motora je veoma složen, jer treba opisati njegove nestacionarne (dinamičke) brzinske karakteristike [31]. Kako ovaj problem nije teorijski razrešen, a imajući u vidu da su za performanse vozila značajne mehaničke (brzinske), a ne termodinamičke karakteristike, u daljem tekstu o njima će biti više reči.

Danas se ispitivanja motora, najčešće, vrše pri konstantnom dovodu goriva, a u slučaju da je on maksimalan, takve karakteristike nazivamo spoljašnjim [19, 32]. Radi ilustracije, na slici 2 prikazan je karakter obrtnog momenta jednog vozila iz proizvodnog programa Zastave [34], čiji će parametri biti korišćeni tokom daljih istraživanja. 


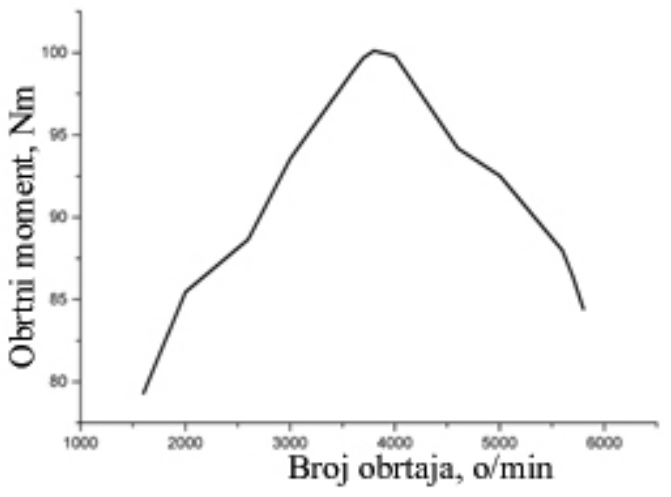

Sl. 2 - Obrtni moment posmatranog motora pri maksimalnom dovodu goriva

Karakteristike motora pri delimičnom dovodu goriva nazivaju se parcijalnim $[11,19,21]$. Proizvođači motora ih najčešće javno ne publikuju, ali su ispitivanja pokazala da se može grubo usvojiti da parcijalne karakteristike motora linearno zavise od količine dovedenog goriva [26], a ova konstatacija je mnogo tačnija kod dizel motora, nego kod benzinskih motora. Imajući u vidu složenost problema i nedostatak eksperimentalnih podataka za posmatrani motor, ocenjeno je celishodnim da se u ovom radu koristi ovo uprošćenje.

Radi daljih analiza, kriva momenta sa slike 2 aproksimirana je polinomima, pri čemu su analize pokazale da polinom petog stepena daje zadovoljavajuću tačnost.

$\mathrm{Na}$ osnovu prethodnog, parcijalne brzinske karakteristike motora su prikazane izrazom:

$$
M_{e}\left(n_{e}, \alpha\right)=M_{e}\left(n_{e}, \alpha_{100}\right) \alpha
$$

gde je:

$\mathrm{M}_{\mathrm{e}}\left(\mathrm{n}_{\mathrm{e}}, \alpha\right)$ - zavisnost obrtnog momenta motora od broja obrtaja i količine dovedenog goriva,
$M_{e}\left(n_{e}, \alpha_{100}\right)$ - zavisnost obrtnog momenta motora od broja obrtaja pri maksimalnom dovodu goriva,

$\alpha$ - upravljačka veličina koja, u suštini, definiše dovod goriva u motor, a kreće se u intervalu $[0,1]$.

Dinamičke brzinske karakteristike motora, najčešće, nisu poznate, a radi ilustracije, na slici 3 prikazano je ponašanje jednog motora pri naglom uvećanju i smanjenju količine dovedenog goriva [26]. Kao što se sa slike vidi, pri naglom „dodavanju gasa“ menja se broj obrtaja, a obrtni moment raste sa kašnjenjem (u konkretnom slučaju 1,5 s), a slično se ponaša i pri „oduzimanju“ gasa. To se može objasniti nedostatkom vazduha kod benzinskih, odnosno kašnjenjem turbine (opet vezano za nedostatak vazduha) kod dizel motora [26]. Egzaktno modeliranje dinamičkih karakteristika motora je, praktično, nemoguće, pa se, za praktične potrebe, vrši aproksimacija eksperimentalnih podataka [13]. Na osnovu slike 3 dinamičke karakteristike mogu se, približno, izraziti u funkciji stacionarnih brzinskih karakteristika motora, uvođenjem jedinične funkcije kašnjenja, tj.:

$M_{\text {edin }}\left(n_{e}, \alpha\right)=M_{e}\left(n_{e}, \alpha\right) h\left(t-t_{m}\right)$

gde je:

$\mathrm{t}$ - vreme,

$\mathrm{t}_{\mathrm{m}}$ - vreme kašnjenja motora (usvojeno $1,5 \mathrm{~s})$,

$h\left(t-t_{m}\right)$ - jedinična funkcija sa kašnjenjem koja ima vrednosti 0 za $\mathrm{t}<\mathrm{t}_{\mathrm{m}}$, a izvan tog intervala 1. 


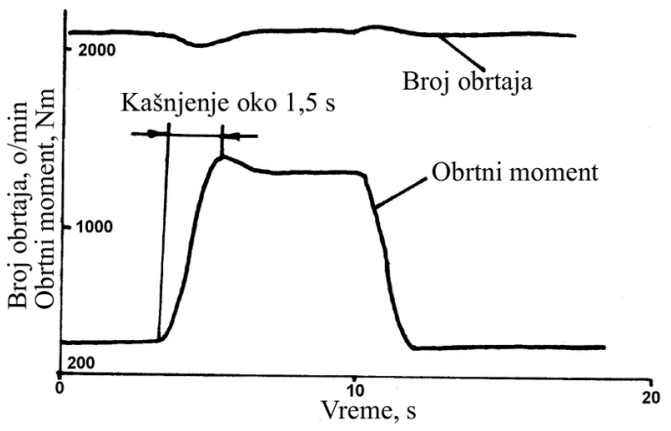

Sl. 3 - Dinamičko ponašanje motora pri nagloj promeni količine dovedenog goriva

Radi lakše analize usvojeno je da pogonska grupa predstavlja kombinaciju idealnog kontinualno varijabilnog menjača, kardanskog prenosa i pogonskog mosta [13, 21]. Karakteristika usvojenog idealnog kontinualno varijabilnog menjača prikazana je na slici 4, a glavni prenosnik imao je prenosni odnos 4 .

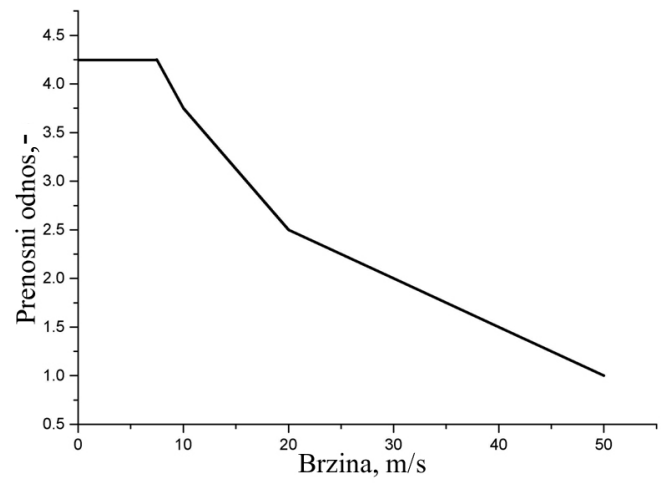

Sl. 4 - Karakteristika idealnog varijabilnog menjača

Napomenuto je da je makroprofil puta, u slučaju pravolinijske deonice, obuhvaćen podužnim nagibom puta. Imajući u vidu uslove puta i karakteristike transmisije, izračunato je ubrzanje vozila $[11,21,30]$ :

$j=\frac{g}{\delta}[D(v)-f(v) \cos u-\sin u]$ gde je:

$\mathrm{D}(\mathrm{v})$ - dinamički faktor,

$\mathrm{f}(\mathrm{v})$ - koeficijent otpora kotrljanja,

$\delta$ - koeficijent učešća obrtnih masa,

u - ugao podužnog nagiba puta (znak ,.-“ za nizbrdicu).

Dinamički faktor izračunat je prema formuli:

$D(v)=\frac{F_{o}-R_{v}}{G}$

Pogonska sila uključuje dinamičke parametre motora date izrazom (2) i transmisije, a data je izrazom:

$F_{o}=\frac{M_{e d i n}\left(n_{e}, \alpha\right) i_{g} i_{o} \eta_{u}}{r_{d}}$

gde su korišćene oznake istovetne onima iz $[11,21,30]$. Detalji izračunavanja dinamičkog faktora poznati su iz [11, 21, 30].

Jednačina (3) omogućava izračunavanje ubrzanja, čijom se integracijom izračunava stvarna brzina vozila.

\section{Modeliranje vozača}

Uloga vozača pri izvršavanju zadatka praćenja brzine tokom pravolinijske vožnje, definisana je optimalnim kontrolerom, čiji su parametri identifikovani metodom stohastičke parametarske optimizacije. Njegove funkcije ne mogu biti posmatrane odvojeno od vozila, pa će u daljem tekstu korišćeni model dinamičkog sistema vozač - vozilo - put biti detaljnije opisan. 


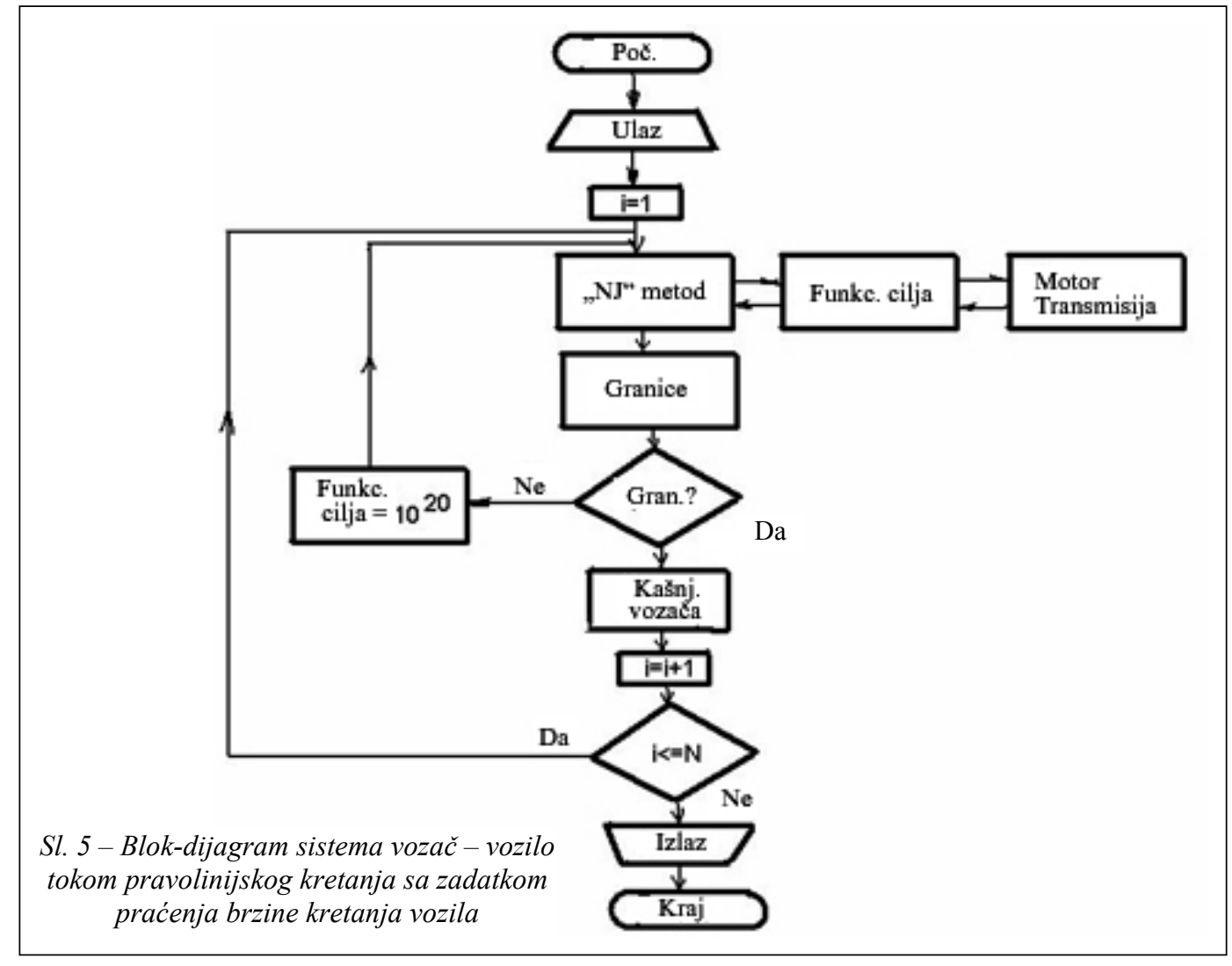

Blok-dijagram modela zasnovanog na metodi optimizacije prikazan je na slici 5. Očigledno je da se u svakom trenut$\mathrm{ku}$, korišćenjem modela motora i transmisije, vrši izračunavanje veličine funkcije cilja (kvadrat razlike željene $\mathrm{v}_{\text {zad }} \mathrm{i}$ ostvarene brzine $\left.\mathrm{v}_{\mathrm{stv}}\right)$, tj:

$$
\Phi=\left(v_{z a d}-v_{s t v}\right)^{2}
$$

Preciznije rečeno, za svaku diskretnu vrednost vremena izračunava se minimalna vrednost funkcije cilja (6).

Završetak iterativnog procesa, $u$ svakom trenutku, realizovan je kada je razlika dve susedne vrednosti funkcije cilja bila manja od $10^{-5}$.
Radi uvođenja konstruktivnih ograničenja za dovod goriva, korišćen je metod spoljašnjih kaznenih funkcija, koji je detaljno opisan u [1-11]. Sva izračunavanja vršena su uz pomoć specijalno razvijenog programskog paketa u Paskalu, a treba naglasiti da je simulacija izvršena u 5000 tačaka, sa korakom od $0,01 \mathrm{~s}$, što je omogućilo dobijanje verodostojnih podataka $\mathrm{u}$ intervalu 0,02 do $50 \mathrm{~Hz}$. Imajući u vidu postavljeni zadatak, to je veoma prihvatljivo [13-29].

$\mathrm{U}$ proces dinamičke simulacije uključeno je i vreme kašnjenja vozača, koje obično iznosi 0,6 do $0,8 \mathrm{~s}$ [18], a u konkretnom slučaju usvojeno je $0,7 \mathrm{~s}$. 


\section{Analiza rezultata dinamičke simulacije}

Da bi testovi razvijenog modela vozača i vozila bili pouzdaniji, usvojeno je da zadata brzina vozila nema nultu vrednost $\mathrm{u}$ početnom trenutku. Time vozač mora najpre da sa vozilom ostvari zadatu brzinu, čija vrednost u tom trenutku nije nula, pa da je u kasnijem periodu prati. Radi analize rezultata razvijenog dinamičkog modela vozača i vozila pri praćenju brzine, tokom pravolinijske vožnje, posmatraće se slike 6 do 10 .

Analizom podataka sa slike 6 može se uočiti da vozilo idealno prati zadatu brzinu do oko $1,5 \mathrm{~s}$, a zatim je srednja brzina nešto manja od željene. Razlozi za ovakvo ponašanje sistema mogu se objasniti kašnjenjem promene obrtnog momenta motora za oko 1,5 sekundi. Imajući u vidu usvojeni karakter dinamičkih karakteristika motora, vozač nastoji da stalno prati zadatu brzinu od $5 \mathrm{~m} / \mathrm{s}$, ali zbog dinamičkih pojava to ne uspeva $\mathrm{u}$ kratkom periodu (svakih 0,01 s). Međutim, na brzinomeru su ove razlike male, pa se može tvrditi da vozilo sa prihvatljivom tačnošću prati zadatu brzinu.

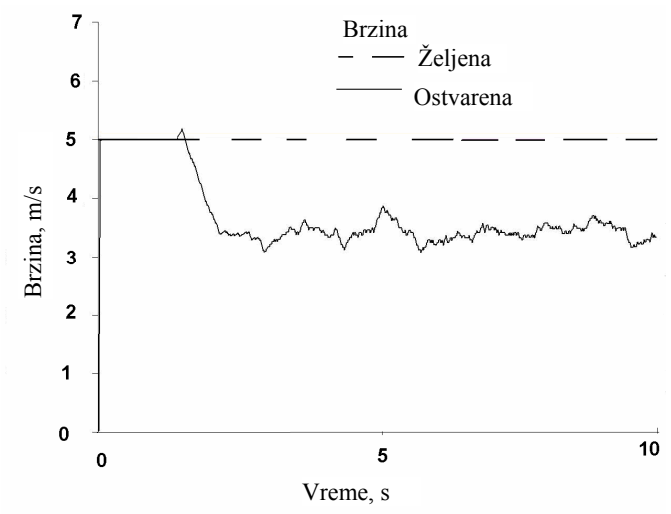

Sl. 6 - Ponašanje sistema u slučaju praćenja brzine na pravolinijskoj uzbrdici

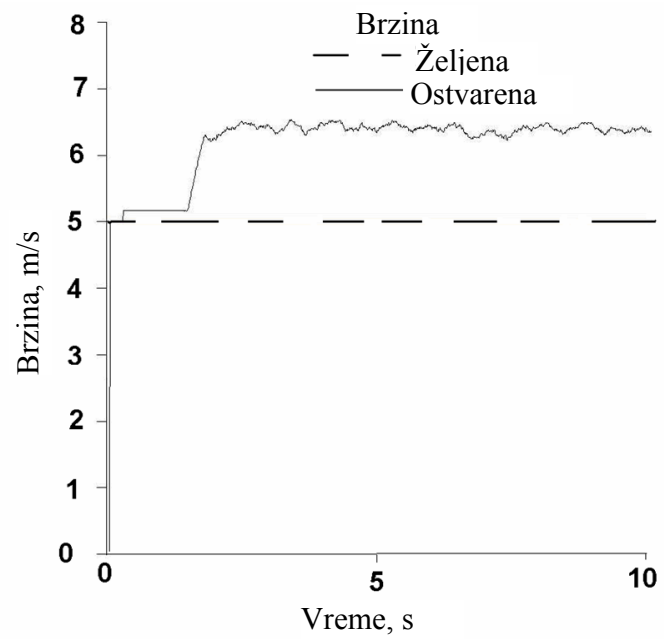

Sl. 7 - Ponašanje sistema u slučaju praćenja brzine na pravolinijskoj nizbrdici

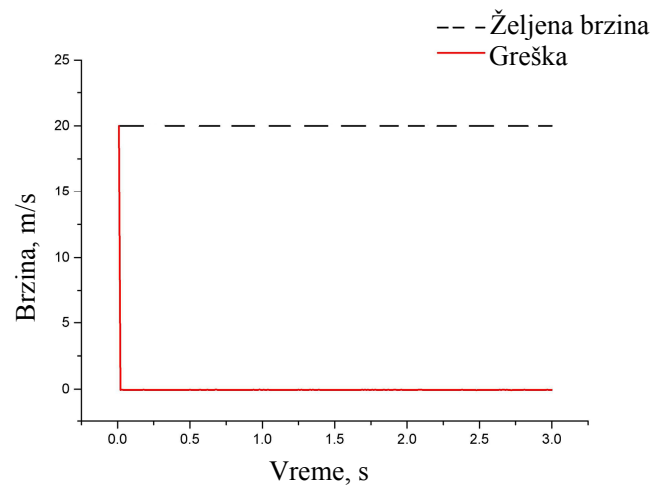

Sl. 8 - Ponašanje sistema u slučaju da je zadato održanje konstantne brzine

Slična je situacija i pri kretanju vozila na pravolinijskoj nizbrdici. Samo u tom slučaju brzina vozila posle 1,5 sekunde je nešto veća, a objašnjenja su identična kao i u prethodnom slučaju, uz napomenu da vozač u slučaju potrebe može aktivirati i kočni sistem, koji u ovom slučaju nije modeliran.

Ponašanje posmatranog dinamičkog sistema pri realizaciji zadatka kretanja konstantnom brzinom od $20 \mathrm{~m} / \mathrm{s}$ na pravolinijskom horizontalnom putu, prika- 
zano je na slici 8, na kojoj je isprekidanom linijom označena željena brzina, a punom linijom odstupanje stvarne brzine od željene. Sa slike je očigledno da je greška bliska nuli, osim u trenutku polaska vozila iz mesta. To ukazuje na to da usvojeni model vozila i vozača veoma dobro simulira ponašanje sistema praćenja konstantne brzine.

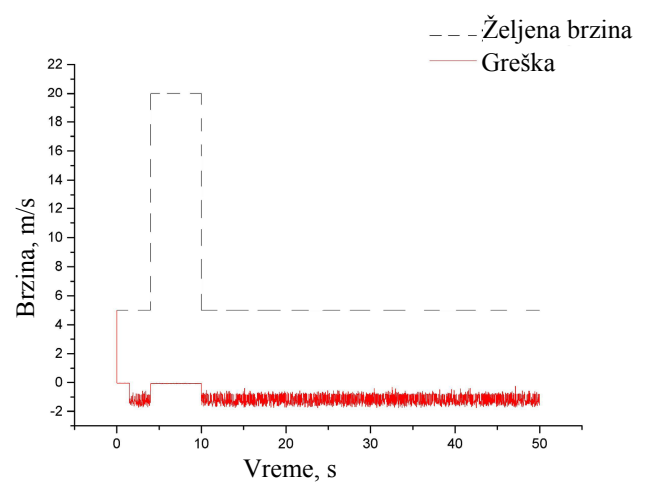

Sl. 9 - Ponašanje sistema u slučaju da je zadato održanje brzine koja se u jednom trenutku naglo menja

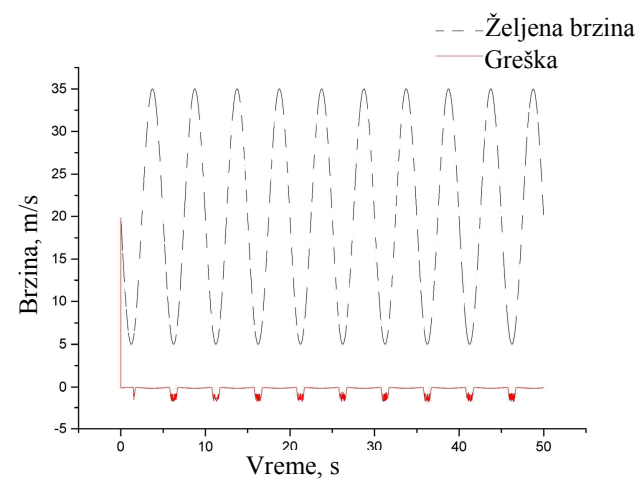

Sl. 10 - Ponašanje sistema u slučaju da je zadato održanje brzine koja se menja po sinusnom zakonu

Slučaj praćenja zadate brzine koja se $u$ jednom trenutku naglo menja prikazan je na slici 9. Simulacija je realizovana za pravolinijsku horizontalnu deonicu puta, a treba istaći da je ovakva promena brzine veoma drastična. Na slici je isprekidanom linijom prikazana željena brzina, a punom odstupanje od te brzine. Očigledno je da je, i u ovom slučaju, usvojeni model imao veoma malu greš$\mathrm{ku}$, osim pri polasku iz stanja mirovanja, jer je stvarna brzina $u$ tom trenutku bila jednaka nuli.

Slučaj praćenja zadate brzine koja se menja po sinusnom zakonu prikazan je na slici 10. Simulacija je realizovana za pravolinijsku horizontalnu deonicu puta, a treba istaći da je ovakva promena brzine, takođe, drastična. Na slici je isprekidanom linijom prikazana željena brzina, a punom odstupanje od te brzine. Očigledno je da je, i u ovom slučaju, usvojeni model imao veoma malu greš$\mathrm{ku}$, osim pri polasku iz stanja mirovanja, jer je stvarna brzina $u$ tom trenutku bila jednaka nuli.

\section{Zaključak}

$\mathrm{Na}$ osnovu izvršenih analiza može se zaključiti da je usvojeni model vozača baziran na teoriji optimizacije, pokazao veoma dobre performanse praćenja zadate brzine vozila, što omogućava njegovu primenu i pri rešavanju drugih zadataka koji su vezani za pravolinijsko kretanje (praćenje zadatog rastojanja, zaustavljanje vozila tokom kočenja i sl.).

\section{Literatura:}

1] Bunday, P.: Basic Optimization Methods, Spottiswoode Ballantyne, Colchester and London, 1984.

[2] Demić, M.: Identification of Vibration parameters for Motor Vehicles, Vehicle System Dynamics, Vol. 27, 1997, pp. 65-88.

[3] Demić, M.: Optimization of Characteristics of Elasto-Damping Elements from Aspect of Oscillatory Comfort and Vehicle Handling, Int. J. of Vehicle Design, Vol. 17, № ${ }^{\mathbf{0}}$, 1996, pp. 76-91. 
[4] Demic, M.: Optimization of Vehicles Elasto-Damping Elements Characteristics From the Aspect of Ride Comfort, Vehicle System Dynamics, Vol. 23 (1994).

[5] Demić, M.: A contribution to optimization of vehicle seats, Int. J. of Vehicle Design, 5/6, 1991, 10 pp. 618-629.

[6] Demić, M.: A contribution to the optimization of the characteristics of elasto-damping elements of passenger cars, Vehicle System Dynamics, Vol. 19, 1990, pp. 3-18.

[7] Demić, M.: Analysis of Influence of Design Parameters on Steered Wheels Shimmy oh Heavy Vehicles, Vehicle System Dynamics, Vol. 26, 1996, pp. 34-379.

[8] Demić, M.: Optimizacija oscilatornih parametara motornih vozila, Monografija, Mašinski fakultet u Kragujevcu, 1997.

[9] Demić, M.: Teorija kretanja motornih vozila, Tehnički fakultet u Čačku, 1999

[10] Demić, M.: Projektovanje putničkih automobila, Mašinski fakultet u Kragujevcu, 2004

[11] Demić, M.: Teorija kretanja motornih vozila, Tehnički fakultet u Čačku, 1999

[12] Elinder, L.: Longitudinal Automotive Driver Models, MSc, Department of Signals and System, Chalmers University of Tecnology, 2005.

[13] Guo, K. At all: Development of a longitudinal and lateral driver model for autonomous vehicle control, In. J. Vehicle Design, Vol 36, No 1, 2004.

[14] Georg, R.: Vehicle Dynamics, Lecture Notes, Fachhochschule Regensburg, 2004.

[15] Ellis, J. R.: Vehicle Handling Dynamics, Mechanical engineering Publications Limited, London, 1994.

[16] Gillespie, T.: Fundamentals of Vehicle Dynamics, SAE, Warrendale, 1992.

[17] Genta, A.: Motor Vehicle Dynamics, Politecnika di Torino, 2003.

[18] Хачатуров, А. А. и др.: Динамика системи: дорогашина-автомобиљ-водитељј, Машиностројеније, Мо- сква, 1976

[19] Хачијан, А. С. и др.: Двигатељи внутреного сгаранија, Техника, Киев, 1968.

[20] Jaginski, R., Flach, J.: Control Theory for Humans-Quantitative Approaches to Modeling Performance, Lawrence Erbaum Assoatiates Publishers, Maywah, New Jersey, London, 2003.

[21] Janković, D. i dr.: Teorija kretanja motornih vozila, Mašinski fakultet u Beogradu, 1990.

[22] Janićijević, N.: Automatizacija sistema motornog vozila, Mašinski fakultet u Beogradu, 1976.

[23] Lee, K., Peng, H.: A Longitudinal Human Driving Model for Adaptive Cruise Control Performance Assessment, Proceedings of IMECE, Symposium on Advanced Automotive Technologies, New Orleans, 2002.

[24] Miliken, W. F. Miliken, D. L.: Race Car Vehicle Dynamics, SAE, Warrendale, 1995

[25] Mitschke, M.: Dynamik der Kraftfahrzeuge, Springer Verlag, 1972.

[26] Milanović, D.: Lična saopštenja, 2007.

[27] Olsen, E.: Evaluating Driver Performance on the Road and in a Simulator, PhD., Sant Jose State University, 1996.

[28] Rothery, R.: Car Following Models, The University of Texas, TX 78712, 2006

[29] Simić, D.: Dinamika motornih vozila, Naučna knjiga, Beograd, 1988

[30] Simić, D.: Motorna vozila, Naučna knjiga, Beograd, 1988

[31] Veinović, S.: Lična saopštenja, 2007.

[32] Veinović, S.: Automobilski motori I, Naučna knjiga, Beograd, 1979.

[33] Zhang, Y.: Scalability of Car Following and Lane Changing Models in Microscopic Traffic Simulation Systems, PhD., The Department of Civil and Environmental Engineering, Southeast University, 2002.

[34] Zastava: Informacije, 2007. 